\title{
The John Crerar Library and Plans for Its New Building
}

BY HERMAN H. HENKLE

Th Then Clement W. Andrews pubY lished his description of a new Crerar Library in 1920 he indicated the extent to which the now forty-year-old structure represented a marked departure from the standard pattern of library architecture. In the intervening years the building and the library within it have become widely known. However, after only four decades the judgement has been made that a new building is needed to serve adequately the changing program of the library.

In a very real sense this decision has been one of the natural conclusions of an intensive review of the library's objectives and policies, which began in 1948. The initial stimulus for this review was rooted in problems of economics, but the direction in which the library has moved was influenced in a large degree by the desire of the board of directors and the administrative officers of the library to re-examine the collections and the service program in the light of current needs for library service within the fields represented by the Crerar collections.

The first stage was an intensive review of the library's acquisitions policy to bring it more sharply into line with the library's original fields of interest: science and technology. A history of the library's acquisitions policy and the detailed statement of the revised policy were published in 1953.1

Economic factors related to the library building have also affected the long-term planning of the library. The principal

1 Acquisitions Policy: A Review of the Policies Governing the Collections of the John Crerar Library, In cluding a Detailed Statement of Current Policy. Chicago: John Crerar Library, 1953.
Mr. Henkle is Librarian, John Crerar Library.

difficulties have been of two kinds. The first difficulty is the cost of physical maintenance of the building, and the second relates to the restrictions placed on the most effective use of space by the distribution of the library over ten floors of its fifteen-story building. This combination of factors led to intensive study of the possibilities of a new structure.

Still another consideration has been the relation of Crerar Library to the general development of libraries in Chicago and the midwest area served by the library. The first serious study of the possibility of a new location took place at the time the Engineering Societies trustees of New York City were considering Chicago as the location for a new Societies building. The decision of the Engineering Societies trustees to remain in New York City closed the possibility of a move in this connection.

Economic problems related not only to maintenance of the building but also to the general support of the library's collections and services led to continued exploration of the possibilities of improving the library's financial situation. One avenue explored was the potential advantage of affiliation with some nonprofit educational institution, including a review of the possibilities of relocation. Out of these considerations came a proposal from the Illinois Institute of Technology, late in 1958, for Crerar Library to relocate on the campus of the Insti- 
tute, which is called Technology Center and is a growing complex of research organizations, including Armour Institute of Technology, the Institute of Gas Technology, and the Central Research Laboratories of the Association of American Railroads. Announcement of the acceptance of the Institute's proposal was issued jointly by the directors of Crerar and the trustees of the Institute in June 1959.

With this decision, studies were begun of the library building needs of the two institutions and of the interinstitutional relations which might assure long-term success of a cooperative library program. These studies ended with the development during 1960 and early 1961 of a general plan for a new library building and in the signing of a long-term agreement in June 1961.

\section{A Joint Program}

The appropriateness of a closer affiliation between the John Crerar Library and the Illinois Institute of Technology was supported by studies of the use of Crerar Library collections, which showed that among the most active users of the Crerar collections the students and research personnel at Illinois Institute of 'Technology and Armour Research Foundation were ranked in first place. This fact, however, was not allowed to overshadow the importance of Crerar's status as a free public library serving the students and research personnel of many other schools and colleges, as well as the library needs of the industrial community. It was soon apparent that an opportunity was being presented to serve more effectively the needs of the educational and research programs carried on at Technology Center and to provide for better facilities for all of Crerar Library's clientele. Each of these central facts was given due consideration in planning the library program which the new building has been designed to serve.

Briefly, the institutional relations incorporated into the plans for the new building and the agreements between Crerar and the Institute are the following:

1. A city block has been reserved for the Crerar Library building for a ninetynine year period, in the heart of the Illinois Institute of Technology campus. This area is directly south of the central business section of Chicago.

2. The new building will be jointly constructed by the two institutions. It will be known as the John Crerar Library building and will be administered under the direction of the board of directors of Crerar Library.

3. The Illinois Institute of Technology will place its library collections in custody of Crerar Library, and the staffs of the two organizations will be merged.

4. Crerar Library will continue to serve as a free public reference library of science, technology, and medicine and, at the same time, provide library services to IIT and its affiliated institutes on a contract basis.

5. A portion of the service area of the library building will be reserved primarily for the use of students and faculty of IIT, but the collections and study facilities of this area will also be accessible to student readers coming to Crerar from other educational institutions.

6. A student-services division will be responsible for supervision of the IIT section of the library and will have in its custody a loan collection for the students

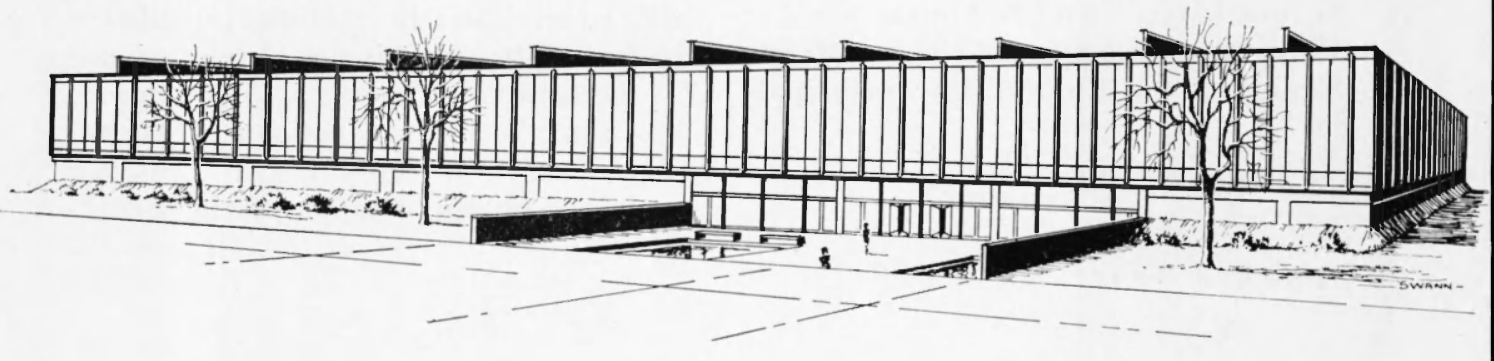




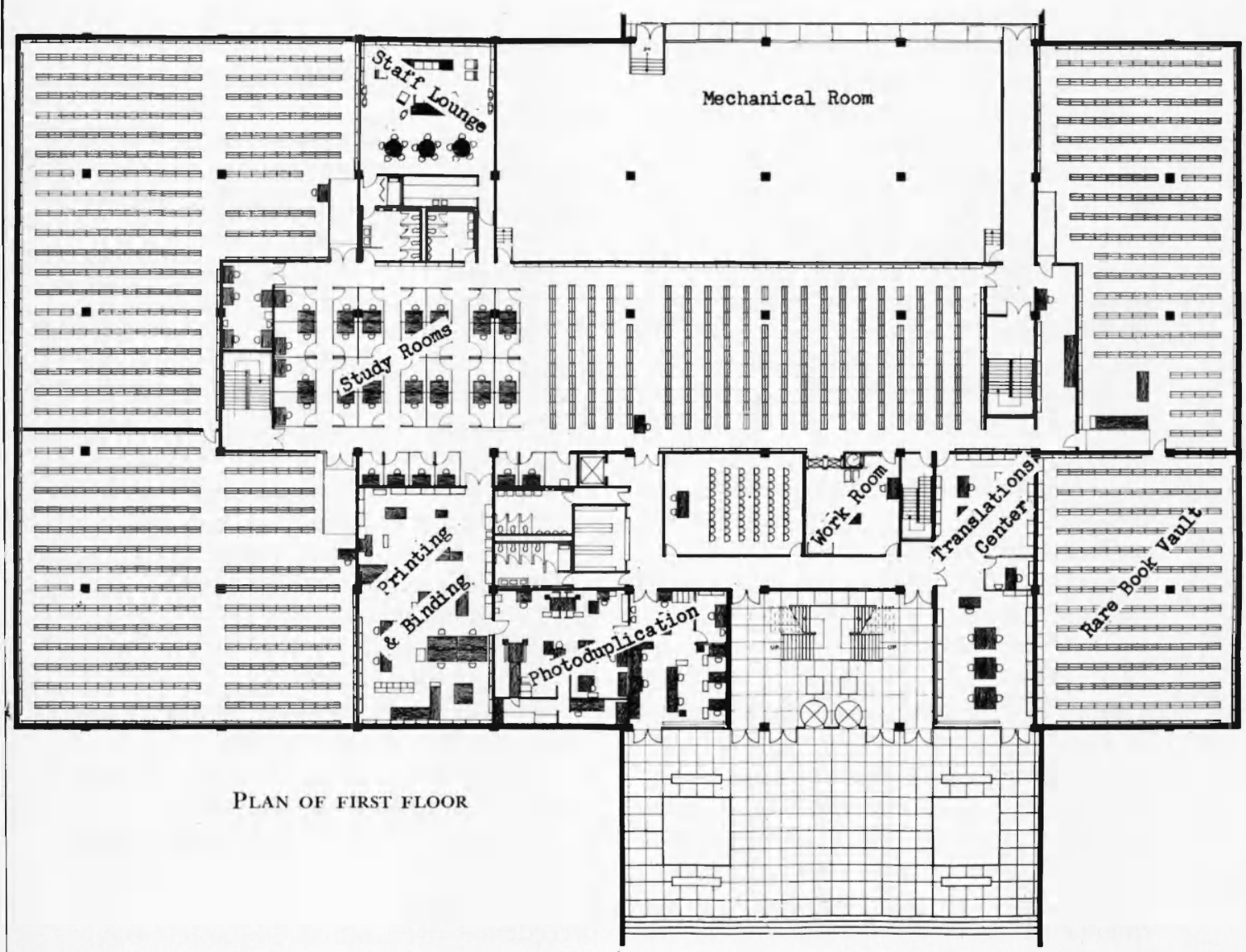

and faculty of the institute. This will be an open-shelf collection of sixty thousand volumes. Consistent with the general policy of Crerar Library serving as a reference library, these books will be available to students from other institutions for reference use only.

7. A research-services division will also have an open-shelf collection of some sixty thousand volumes for reference use of all research personnel making use of Crerar Library.

\section{The Building Program}

A marked trend in the planning of new university library buildings has been provision of separate facilities for library service to undergraduate students and to graduate students and research person- nel. No such distinction has been possible in the organization of service facilities in Crerar Library although studies of reader use have shown that approximately one-half of the use of the library's collections is by undergraduate students in technical schools and colleges. Observations by the professional staff of the library over several years have led to the conclusion that services to research personnel could be greatly improved if separate facilities were provided for the two groups of library users.

The opportunity to plan a new library building opened the way to planning separate service facilities for student and research user groups of Crerar Library clientele. Conferences with representatives of the teaching and research staffs at 
IIT brought expression of approval of such a plan from the point of view of various groups located at Technology Center. Accordingly, a basic decision in the program for the new building was to establish separate divisions for student services and research services.

A second important objective related to accessibility of the book collections to readers. It was accepted as axiomatic that an open-shelf collection is essential to the use of the student-services division. It was also concluded that, in the light of concentrated use of research literature in relatively recent publications, it would be possible to provide an open-shelf collection for research personnel that would meet a high proportion of their library needs, especially if access could be given to a substantial proportion of the actively-used back files of periodicals.

It was recognized at the same time that a substantial proportion of the collection is infrequently or rarely used. The problem in programing the building was to identify as closely as possible the rough percentages of the collections that would be represented in the several categories of publications grouped according to frequency of use. Several studies of the use of the collections have already been made, and additional study will be devoted to this field before the final assignment of location is made to the various titles now in the collections of Crerar Library and IIT.

General guide lines in the building program, then, for housing the collections were (1) that space for approximately sixty thousand volumes would be provided in each service division for open shelf collections; (2) that additional limited-access stack space would be provided for research personnel to less frequently used but still actively needed portions of the book and journal collections: and (3) that closed stack space would be provided for the remainder of the collections, in two sections: first, a fireproof vault area for rare and un- usually valuable books, and, second, a closed-stack area for other little used portions of the collections, shelved in compact storage.

A third major objective in the building program was to provide space and facilities for close coordination of public catalogs, bibliographical resources, and the loan and reference services. The objective was to bring each of these facets of research library services into as close association with each of the others as utilization of space could provide. And a fourth major objective was to locate library personnel making intensive use of the catalog and bibliographical resources of the library as closely as possible to these facilities.

These four major objectives dominated the planning of the new building for Crerar library: (1) separate study areas for students and researchers, (2) accessibility of frequently used books to each of these reader groups, (3) close coordination of public catalogs, bibliographical resources, and loan and reference services, and (4) accessibility of catalogs and bibliographies to library personnel making intensive use of them; and each took precedence over other desirable objectives for a library program whenever conflicts between them could not be resolved.

The complex of all decisions on the program for the library building include all of the normal factors which are taken account of in library building planning. There was, however, one major determining factor which was added to the four indicated above and which represented a departure from traditional library building planning. This was a decision by the board of directors that the building would provide space for only five years' growth of the collections beyond the move-in date. The basis for this decision was that the advancing technologies for miniaturizing texts give sufficient promise of becoming economically competitive with the cost of book stack construction to justify such a sharp 
break with library building tradition. Inherent in the decision were the expectations that intensive studies will be made of microfilm equipment and techniques, and possibly other techniques for miniaturizing library materials, and that additional book storage facilities will be built if these investigations prove unsuccessful.

\section{The: Builidnc; Plan}

Designed by the architectural firm of Skidmore, Owings, and Merrill, the library will be a two-story building 160 $\times 282$ feet, with total floor area of 92,160 square feet. The cost of the building will be approximately $\$ 2,000,000$, including furniture and equipment.

The ground floor will be windowless except for the center portion of the front of the building. The second floor, which encompasses the main service areas, will be completely enclosed in gray glass walls from floor to ceiling. The ground floor is of modular construction with supporting pillars on 32-foot centers. The second floor is of cantilever construction, which provides unusually large unbroken areas in the public service portions of the building, with almost complete physical mobility for the arrangement of books, readers, library personnel, and bibliographical equipment. The building will be completely air-conditioned and is scheduled for occupancy in September 1962.

The first floor will be devoted primarily to book stacks with parts of the floor devoted to study rooms, staff rooms, a conference room, and three operating departments: printing and binding, photoduplication service, and the Special Libraries Association Translations Center.

The second floor will include the two reader-service divisions, research information service, the cataloging and acquisitions departments, a rare book room (the Crerar Room), and administrative offices. Points of special interest in the researchservices area are the ready accessibility of the public catalog to technical processing personnel of the library as well as to

PLAN OF SECOND FLOOR

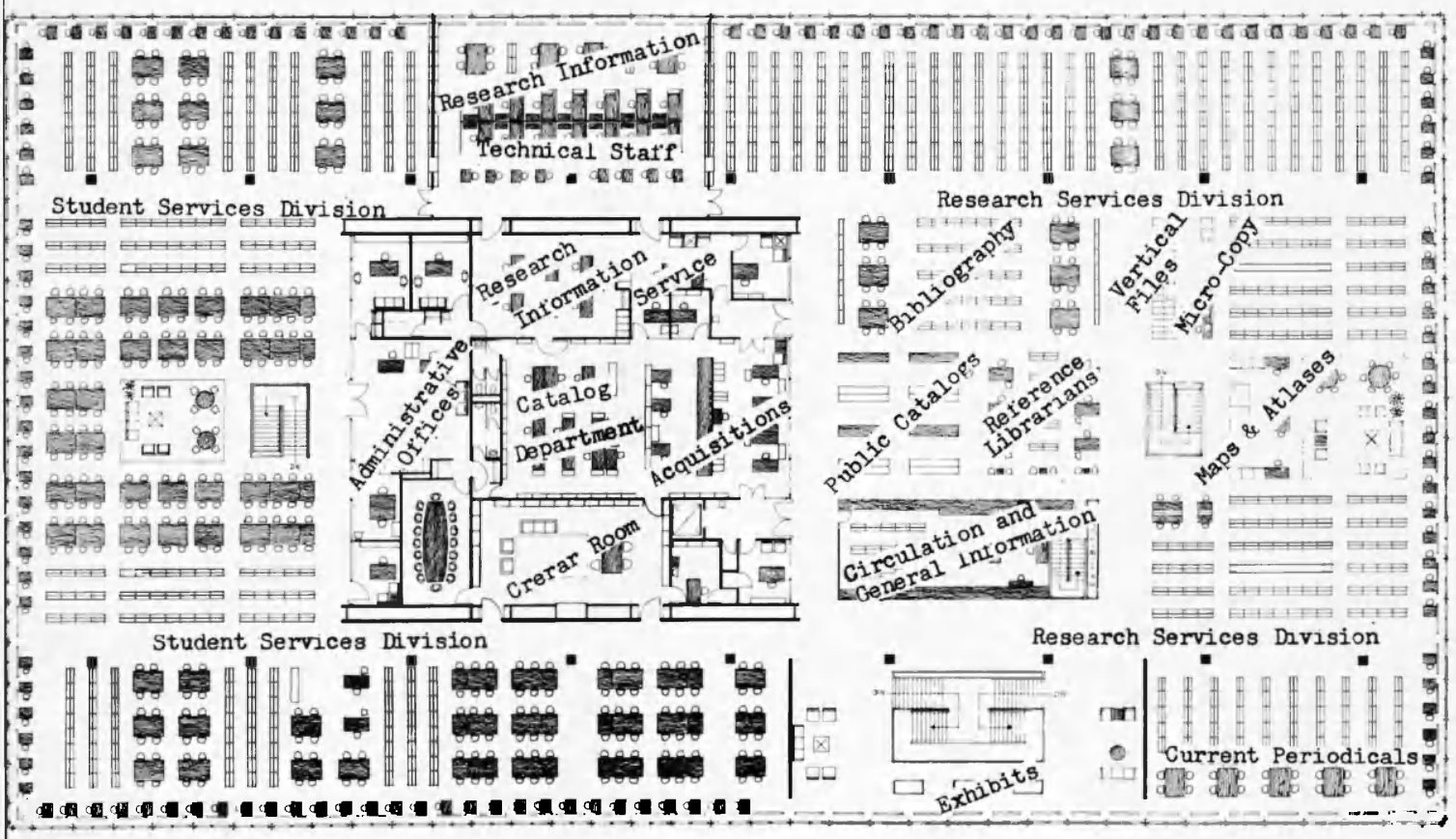


reference librarians and readers; the close integration of catalogs, bibliographical collections, and reference librarians for ready access by readers; a bibliography section which will accommodate a collection of more than six thousand volumes, and individual study tables provided for a large portion of the reader capacity.

A note on the organization of reader services may be of interest in connection with its effect on the arrangement of the facilities in this area. A three-months' analysis of inquiries received by the reference librarians led to the conclusion that both readers and reference librarians would profit by establishment of a general information center designed to absorb a large portion of the routine inquiries which presently require much of the attention of the reference librarians. This general information service will be provided by a general information and circulation department whose activities will be centered at the circulation desk.

Installation of an automatic telephone exchange within the library will permit location of a desk-panel switchboard in the general information center to handle a large portion of routine inquiries received from outside of the library, exclusive of those coming from the various institutes in Technology Center. The present automatic dial telephone system

\section{Micropublishing}

Several years ago, the Resources Committee of the Resources and Technical Services Division of ALA established a Subcommittee on Micropublishing Projects. The function of this subcommittee is: "To serve as a coordinating agency for both libraries and publishers of microforms; to advise on the desirability of proposed publishing projects; to recommend micropublishing projects which will serve the needs of the scholarly community; to take appropriate action to insure a desirable quality of reproduction and bibliographic control."

Since its inception, the subcommittee has in Technology Center and the system to be installed in the library will have intercommunicating connections which will eliminate most of this communication load from the library's switchboard.

Another major change in service which is incorporated in the plans for the new building is the elimination of the library's present subject departments (medicine and technology) and the integration of research service now given in these two departments through a group of subject specialist or science librarians.

The only service center common to both the student-services and researchservices divisions is the general information and circulation department. Except for this common point of service, the student-services division is planned to be as nearly self-sufficient as possible in card catalog, reference books, bibliography, current periodicals, current books, and reference services required for technical education at the undergraduate level. But it is also planned that any student working on advanced assignments requiring more intensive bibliographical research and a wider selection of scientific and technical publications will have access to the bibliographical and reference collections and to the public catalogs in the research services division. been called upon for advice by a number of libraries which were either concerned about the quality and inclusiveness of an announced micropublishing project or were formulating policy statements to guide them in allowing commercial micropublishers access to their collections.

The subcommittee will welcome inquiries from libraries or from commercial micropublishers concerning the advisability of a project or recommendations concerning bibliographic control. James E. Skipper, librarian of the University of Connecticut, Storrs, is chairman of the committee. 